\title{
Molecular detection and identification of fatal infectious agent, isolated from patients in an outbreak occurred in Sistan \& Balochistan province of Iran
}

\begin{abstract}
An outbreak of tularemia or plague like syndrome occurred in the province of Sistan and Balochistan of Iran, from May to June 2007. Tularemia and plague had not been reported in this region for last 100 years and before. Thirteen eight cases were identified with ulcer glandular syndrome dominant to all cases with age from children to elderly ages. With fatality rate of $26 \%$ and death of 8 patient that have been reported by villagers very late, all other patients and new cases recovered after antibiotic therapy and other heath measures to prevent the spread of diseases. Targeted chemoprophylaxis, sanitation, and vector control played a crucial role in controlling the outbreak. Coco bacillus like agents was isolated from the blood samples of the patients. Epidemiologic, microbiological and molecular analysis of samples findings suggested the possible existence of a local animal reservoir, food or water contamination during this period, but its origin could not be determined. This sudden and unexpected reemergence of tularemia or plague like disease in this province with no background history of rodents or other animal death from the disease or any human cases is important for molecular epidemiology and root finding.
\end{abstract}

Volume 7 Issue $3-2019$

\author{
Ali Karami, Fateme Pourali \\ Research Center of Molecular Biology, Baqiyatallah University of \\ Medical Science, Iran
}

Correspondence: Ali Karami Ph.D, Research Center of Molecular Biology, Baqiyatallah University of Medical Science. P.O. Box 19945-58I, Tehran, Iran, Email Karami@bmsu.ac.ir

Received: April 24, 2019 | Published: May 30, 2019

\section{Introduction}

Tularemia is a highly infectious disease which can be caused by a small amount of bacteria; it is naturally occurring. Typically found in rural areas, it is common in animal populations, and functions as a zoonosis if transmitted via the bite of an infected animal (in particular rodents, rabbits, and hares), or if transmitted via a tick or deer fly bite. ${ }^{1}$ The disease can be contracted through the handling inhaling the bacteria which causes the illness. If inhaled and left untreated, it can lead to severe respiratory illness, pneumonia, and systemic infection. Tularemia, a zoonotic disease caused by the highly infective, virulent, non-sporulating Gram-negative coccobacillus Francisella tularensis It is a very small bacterium, 0.7-1.0 microns in length, that is nonmotile and does not form spores... the organism can be isolated from contaminated environmental sources such as water and mud. ${ }^{2}$ Humans can become infected with tularemia through many different routes, and age and sex factors do not seem to affect susceptibility. Common routes of infection are: through insect bites including ticks and mosquitoes, handling of contaminated animal tissue or fluid, recurrent contact act with contaminated water, food or soil, halation of infective aerosols.

Tularemia has a 3-5 day incubation period and the initial symptoms are flu-like in nature. These symptoms include: sudden fever, chills, headache, diarrhea muscle aches, dry cough, and progressive weakness. Other symptoms are more specific and depend on the route of infection. Skin ulcers and swollen glands may occur through coetaneous exposure to tularemia. Pneumonic tularemia occurs when the bacteria is inhaled. Symptoms for this form of tularemia include chest pains, bloody sputum and difficulty breathing. ${ }^{2}$ Francisella tularensis infection occurs in Iran is supported by a study published in 1973, that serological evidence of infection was found in animals scattered throughout. ${ }^{3}$ There is no data on epidemiologic or presence of tularemia cases in sistan and baluchestan provinces.
Plague is primarily a bacterial zoonosis affecting rodents. It is caused by Yersinia pestis and is transmitted from animal to animal by fleas. Humans usually become infected through the bite of an infected rodent flea, inhalation of infected aerosols or ingestion of contaminated food and water. Bubonic plague, a severe infectious disease which, in the absence of appropriate antimicrobial drug therapy, can evolve to a rapidly fatal septicemia or pneumonia, can develop. A pneumonia form, which enables direct transmission to contacts, can be responsible for highly lethal outbreaks. ${ }^{4}$ Currently, plague natural foci persist in Asia, the Americas, and Africa (where most human cases occur). ${ }^{5}$ Plague foci have previously existed in the Kurdistan province of Iran. ${ }^{6}$

The surveillance of territories surrounding the plague focus of Kurdistan province in Iran, by inspection of wild rodent burrows, permit to reveal the existence of an epizootic in a new focus located in the Eastern Azerbaijan province, where plague was never reported. In one study 14 strain of $Y$. pestis were isolated from Different rodents and from the fleas. The eventual relationship between these two areas separated by about $200 \mathrm{~km}$ was investigated: neither attempts to isolate $Y$. pestis nor serological surveys permit to reveal any sign of plague enzootic in the zone between the Kurdistan focus nor the new described focus of the Eastern Azerbaijan. ${ }^{7-10}$ There is no report of plague in Sistan and baluchestan of Iran.

\section{Methods}

Sistan-Balochistan province is located in extreme southeastern Iran. The combined Sistan and Baluchestan province today accounts for one of the driest regions of Iran. During May and Jun 2007, several patients with signs of severe infection and painful inflammatory adenopathy were admitted to the health branch of. Khash, saravan and other local health care centers. After eliminating all other possible differential diagnoses, clinicians suspected tularemia. Blood samples collected from patients were sent to the Microbiology Department of Zahedan tropical disease laboratory and Institute Pasteur of Iran. All samples were examined with standard bacteriologic methods. 
Direct examination of smears was performed after Wayson and Gram staining. Blood samples were cultured in Castaneda medium and examined daily. Further subcultures and biochemical tests were performed according to standard microbiological protocols.

\section{PCR analysis}

PCR was performed on DNA extracted from isolated bacteria from blood cultures. We have uses primers specific for F1 gene of the yersinia pestis as bellow protocols:

\begin{tabular}{ll}
\hline DNA template & $\mathrm{Iml}$ \\
Primer F & $\mathrm{Iml}$ \\
Primer R & $\mathrm{Iml}$ \\
DNTPs & $2 \mathrm{ml}$ \\
MgCl2 & 0.75 \\
PCR buffer I0X & 2.5 \\
Taq DNA pol & 0.5 \\
D.D.W & upto 25 \\
\hline
\end{tabular}

PCR program

\begin{tabular}{llll}
\hline Stage & temp. $^{\circ} \mathbf{C}$ & time $(\mathrm{min})$ & cycle no. \\
\hline Hot start & 94 & 5 & \\
Denat. & 94 & $\mathrm{I}$ & \\
Annea. & 62 & $\mathrm{I}$ & 35 \\
Exten. & 72 & $\mathrm{I}$ & \\
Final Ext & 72 & 7 & \\
\hline
\end{tabular}

\section{Nested PCR}

We have used inner primers specific for the $\mathrm{F} 1$ gene sequence to confirm the PCR product. The protocol is the same as above (Table 1).

Table I Biochemical characteristic of different biovars of Yersinia pestis, Iranian type is identified as Mediavalis

\begin{tabular}{lllll}
\hline Biovar & Glycerol & Arabinose & Nitrate & $\begin{array}{l}\text { PCR and } \\
\text { nested PCR }\end{array}$ \\
\hline Antique & + & + & + & + \\
Mediavalis + & & + & - & + \\
Orientalis & - & + & + & + \\
Microtus & + & - & - & + \\
Zahedan-khash & + & - & +
\end{tabular}

\section{Sequencing}

For final confirmation, PCR product was sequences and nucleotide sequence were analyzed by Bioinformatics programs like BLAST to compare the sequence with databases (Table 2).

\section{Results}

Samples taken from members of one family in the same village, reveled several Gram negative coocobacill shape bacteria similar to Francisella tularensis and Yersinia pestis. Further bacteriological analysis In Institute Pasteur in Teheran demonstrated that bacteria are more similar to Yersinia pestis with Negative in Nitrate reduction and positive in Arabinose. Diagnosis of plague was suspected and confirmed by isolation of a bacterial DNA and molecular analysis. Figure 1 demonstrates the PCR product of $530 \mathrm{bp}$ from F1 gene of the Yersinia pestis. Figure 2 is result of Nested PCR with inner primers to f1 gene and as its shown 2 fragment of 530 bp original gene and 280 $\mathrm{bp}$ is shown. The sequencing and PCR data demonstrate that Bacteria had F1 gene sequence (Figure 3-5).

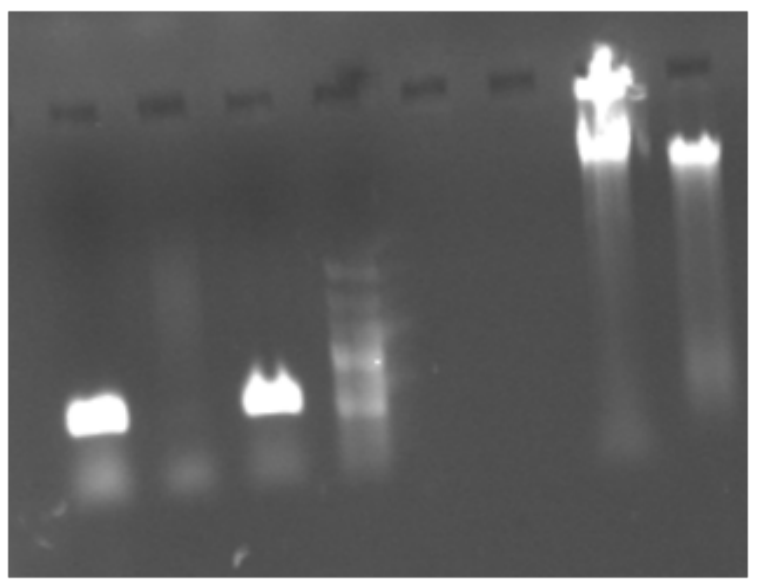

Figure I PCR of DNA extracted from bacteria isolated from Blood culture of patients . Primers FI and RI from gene specific to Yersinia pestis.

I. PCR product of patient no I,

2. Negative control,

3. Positive control.

4. Molecular marker

5 and 6. Total DNA extracted from bacterial samples.

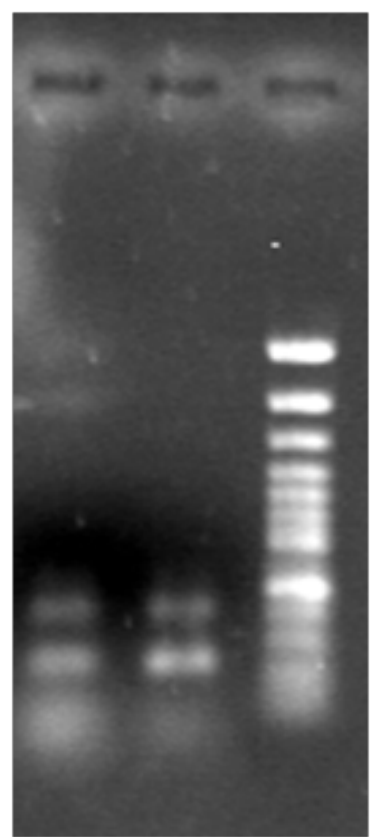

Figure 2 Nested PCR of the product from first PCR with inner primers. I. Sample from PCR I, two correct fragments is visible 2. Positive control DNA,

3. MW 
>PCR product Yersinia pestis plasmid pMT size: $540 \mathrm{bp}$

A A T T GCG GAATTCTTATTGGTTAGATACGGTTACGGTTACAGCATCAGTGTATTTACCTGCTGCAAGT TTACCGCCTTTGGAACCAATTGAGCGAACAAAGAAATCCTGGCTGCCCGTAGCCAAGACGACGTCATC C C C CACAAGGTTCTCACCGTTTACCTTAGGAGAGATATCAAAATCTCTAGAATCCTTGCCAATCACTT

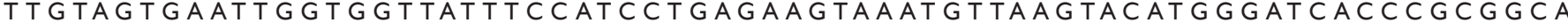
TCTGTAAAGTTAACA GATGTGCTAGTGGTTCCTGTTTTATAGCCGCCAAGAGTAAGCGTACCAACAAG TAATTCTGTATCGATGTTTCCATTGTCCATAATTGTAATTGGAGCGCCTTCCTTATATGTAAGAGTGA T G C G G G C T G G T T C A A C A A G A G T T G C C G T T G C A G T G G T G C T T G C A G T TAAATCT G C C G CAT TAG CA G T GCAATAGTTCCAAATAATGCAATGGCGATAACGG AACTGATTTTTTTCATATGTTACCTCAAAG

Figure 3 Nucleotide sequence of PCR fragment.

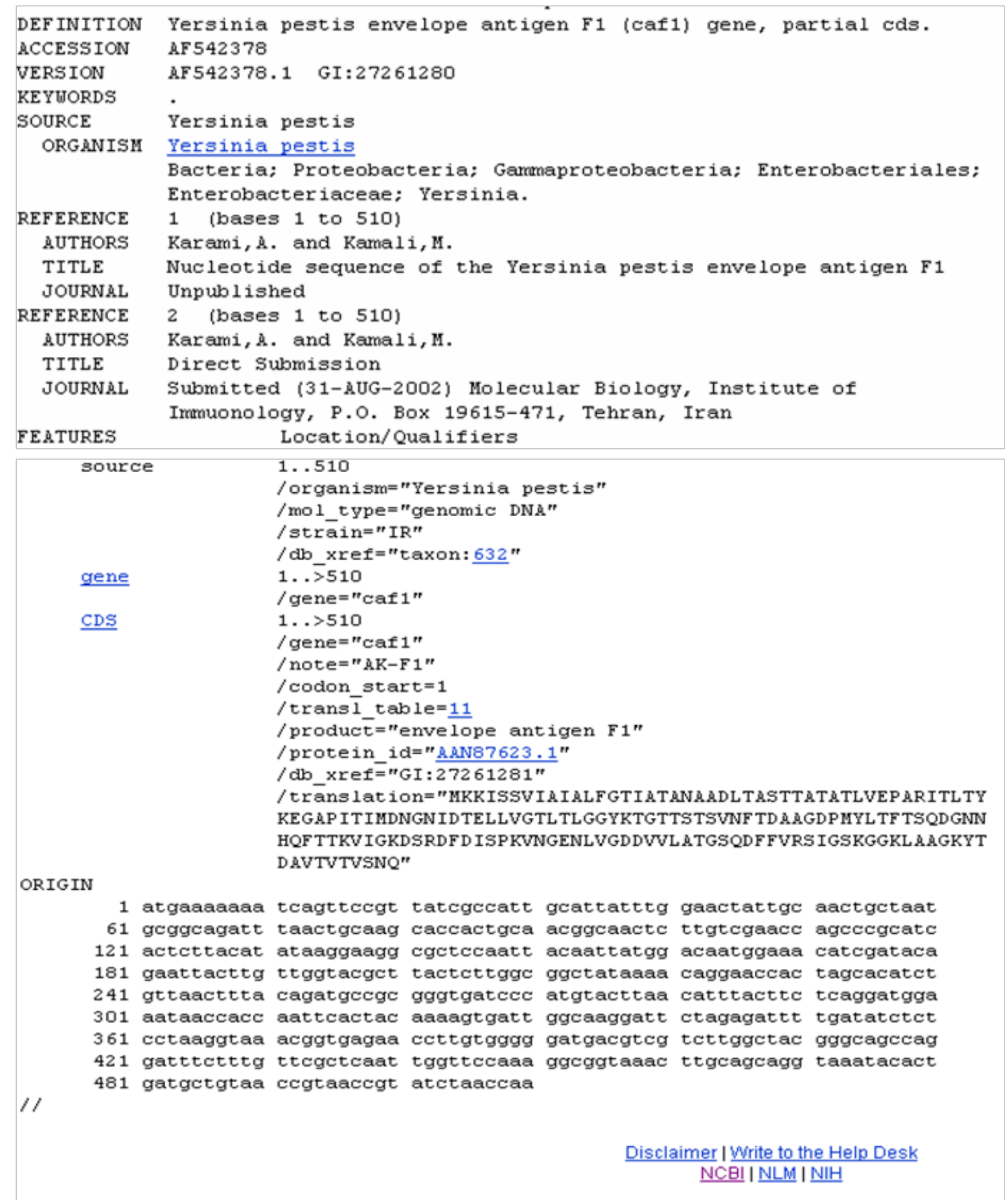

Figure 4 Blast Comparision of PCR Sequence with Gen bank, reveals the 100\% similarity of tested DNA with Yersinia pestis FI gene. 


\begin{tabular}{|c|c|c|c|c|c|c|c|}
\hline $0 . \mathrm{SEQ}$ & 51 & ACTATTGCAA & CTGCTAATGC & GGCAGATTTA & ACTGCAAGCA & CСACTGCAAC & 100 \\
\hline 1. SEQ & 51 & ACCACAGCAA & CTGCTA---- & 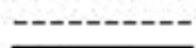 & & --- & 100 \\
\hline 2. SEQ & 51 & ACTATTGCAA & CTGCTAATGC & GGCAGATTTA & ACTGCAAGCA & ССАCTGCAAC & 100 \\
\hline 3. SEQ & 51 & ACTATTGCAA & CTGCTAATGC & GGCAGATTTA & ACTGCAAGCA & CСACTGCAAC & 100 \\
\hline 42B90 1. SEQ & 51 & ACTATTGCAA & CTGCTAATGC & GGCAGATTTA & ACTGCAAGCA & ССАCTGCAAC & 100 \\
\hline 5. SEQ & 51 & ACTATTGCAA & CTGCTAATGC & GGCAGATTTA & ACTGCAAGCA & ССАСТGCAAC & 100 \\
\hline 7. SEQ & 51 & ACTATTGCAA & CTGCTAATGC & GGCAGATTTA & ACTGCAAGCA & ССАСТGCAAC & 100 \\
\hline 8. SEQ & 51 & ACTATTGCAA & CTGCTAATGC & GGCAGATTTA & ACTGCAAGCA & CCACTGCAAC & 100 \\
\hline 9. SEQ & 51 & ACTATTGCAA & CTGCTAATGC & GGCAGATTTA & ACTGCAAGCA & ССАСТGCAАC & 100 \\
\hline GORGIA. SEQ & 51 & ACTATTGCAA & CTGCTAATGC & GGCAGATTTA & ACTGCAAGCA & ССАСТGCAAC & 100 \\
\hline KARAMI. SEQ & 51 & ACTATTGCAA & CTGCTAATGC & GGCAGATTTA & ACTGCAAGCA & ССACTGCAAC & 100 \\
\hline PMT1. SEQ & 51 & & & & & & 100 \\
\hline \multirow[t]{2}{*}{ R. SEQ } & 51 & & & & & & 100 \\
\hline & & 110 & 120 & 130 & 140 & 150 & \\
\hline 0. SEQ & 101 & GGCAACTCTI & $\mathrm{AG}$ & CCCGCATCAC & TCTTACATAT & AAGGAAGGCG & 150 \\
\hline 1. SEQ & 101 & & GTTGA & CCAGAAT & ACTT & GGTG & 150 \\
\hline 2. SEQ & 101 & GGCAACTCTT & GTTGAACCAG & CCCGCATCAC & TCTTACATAT & AAGGAAGGCT & 150 \\
\hline 3. SEQ & 101 & GGCAACTCTI & GTTGAACCAG & CCCGCATCAC & TCTTACATAT & AAGGAAGGCG & 150 \\
\hline 42B90 1. SEQ & 101 & GGCAACTCTT & GTTGAACCAG & CCCGCATCAC & TCTTACATAT & AAGGAAGGCG & 150 \\
\hline 5. SEQ & 101 & GGCAACTCTT & GTTGAACCAG & CCCGCATCAC & TCTTACATAT & AAGGAAGGCG & 150 \\
\hline 7. SEQ & 101 & GGCAACTCTT & GTTGAACCAG & CCCGCATCAC & TCTTACATAT & AAGGAAGGCG & 150 \\
\hline 8. SEQ & 101 & GGCAACTCTT & GTTGAACCAG & CCCGCATCAC & TCTTACATAT & AAGGAAGGCG & 150 \\
\hline 9. SEQ & 101 & GGCAACTCTT & AACCAG & CCCGCATCAC & TCTTACATAT & AAGGAAGGCG & 150 \\
\hline GORGIA. SEQ & 101 & GGCAACTCTI & GTTGAACCAG & CCCGCATCAC & TCTTACATAT & AAGGAAGGCT & 150 \\
\hline KARAMI. SEQ & 101 & GGCAACTCTT & $\mathrm{AG}$ & CCCGCATCAC & TCTTACATAT & AAGGAAGGCG & 150 \\
\hline PMT1. SEQ & 101 & & & & & & 150 \\
\hline \multirow[t]{2}{*}{ R. SEQ } & 101 & & & & & & 150 \\
\hline & & 160 & 170 & 180 & 190 & 200 & \\
\hline $0.5 E Q$ & 151 & CTCСAATTAC & AATTATGGAC & AATGGAAA & TCGATACAGA & ATTACTTGTI & 200 \\
\hline 1. SEQ & 151 & СТССАATA & CATTATGGAT & AATGGCAATA & TCGACACAGA & GCTICTAGTI & 200 \\
\hline 2. SEQ & 151 & СТССААТТАС & AATTATGGAC & AATGGAAACA & TCGATACAGA & ATTACTTGTI & 200 \\
\hline 3. SEQ & 151 & СТССАATTAC & AATTATGGAC & AATGGAAACA & TCGATACAGA & ATTACTTGTT & 200 \\
\hline 42B90 1. SEQ & 151 & СТССААТT & AATTATGG & AATGGAAA & TCGATACA & ATTACTTGTT & 200 \\
\hline
\end{tabular}

Figure 5 Multiple sequence similarity analysis of sequence of PCR product with several FI gene sequence for different biovars of Yersinia pestis.

Table 2 Analysis of primer used in this study

\begin{tabular}{|c|c|c|}
\hline Sequences producing significant alignments & (bits) & Value \\
\hline gi | 3975477 | | gb | AY450847.I | Yersinia pestis strain 482 plasm___- & 48 & $4 e-04$ \\
\hline gi | 39754755 | gb | AY450846. I | Yersinia pestis strain I35 | piss____ & 48 & $4 \mathrm{e}-04$ \\
\hline gi | 3975475 | | gb | AY450845 . I | Yersinia pestis strain EV plasmi___. & 48 & $4 e-04$ \\
\hline gi | 3883003 | gb | AF 0746 I I _ I | Yersinia pestis is KM plasmid pliT - I _ _ _ & 48 & $4 e-04$ \\
\hline gi | 2996286 | gb | AF 053947 _ I | Yersinia pestis is KM plasmid OTT I, _ _- & 48 & $4 e-04$ \\
\hline gi | 4535724 | I gb | AE0 I7045_I | Yersinia pestis biovar Mediaeval ___ & 48 & $4 e-04$ \\
\hline gi | 5834685 | am:do | AL I 172 I I _ I | YP PliT I Yersinia pestis C092 plasm____ & 48 & $4 e-04$ \\
\hline gi | 5253798| | emb | AJ 698720_ I | Yersinia pestis pG8786 plasmid & 48 & $4 e-04$ \\
\hline gi | 48620 | emb | X61996.I |YPCAFY. pe se is genes call, caf।M, caf _ & 48 & $4 e-04$ \\
\hline
\end{tabular}




\section{Discussion}

Epidemiologic investigation did not identify any other tularemia or plague patients before this outbreak. It is unlikely that other cases occurred and remained undetected during this period. It seems that bacterial agent gives severe infection with high fatality rates. In this investigation we used molecular methods to diagnose identify the infectious agent of unknown origin for the first time. This coordinated experience to rapidly diagnose and contain the severe fatal infection by using molecular methods can be uses for any other similar situations. The bacteriologic diagnosis is a long procedure (at least 4 days) and, in this epidemic molecular method contributed to the effectiveness of the response. The outbreak occurred in a poor rural area of Khash and Saravan villages, with inadequate sanitation. The resident's interview revealed increase in the population of commensal rodents but no unusual rodent mortality was noted during the weeks preceding the outbreak

A crisis management program was developed based on standardized case management, prophylactic treatment and follow-up of contacts sharing the patients, and vector control. No natural focus of tularemia or plague had ever been described in these provinces. Assumption for the original sources of infection have been claimed as contaminated meat, possible source of rabbit or other hunted animals or transported goat from border so the reappearance of human cases in this area can be explained in 3 ways: a recent importation of infected animals, contaminated meat from hunting or a sudden manifestation of a natural focus that had remained silent for decades and finally possible bioterrorist act. These has been observation and claims by villagers and officials of the region of unknown disease and death of goats in the villages central to the epidemic and other rural areas. Preliminary examination of few carcasses fund in the region by Veterinary member of the group did not ravel any evidence but there is no scientific report of tests or laboratory analysis of samples from these carcasses. So, it is not possible to exclude any of this assumption without further molecular epidemiology of the region and exact examination of samples from animals, rodents, vectors, water and environmental samples and follow up of rural population by serology tests. The outbreak occurred at the region with no cultivation or agricultural activity. The current challenge in terms of public health is to determine the source, genotype and the type exposure of people to the infectious agent.

\section{Acknowledgments}

We are grateful to Dr. Izadi President of the University Of Medical Science Of Zahedan and his team members for their support and kindness, and other members of the epidemiology team for their assistance.

\section{Conflicts of interest}

Author declares that there is no conflict of interest.

\section{References}

1. Petersen JM, Schriefer ME, Gage KL, et al. Methods for Enhanced Culture Recovery of Francisella tularensis. Appl Environ Microbiol. 2004;70(6):3733-3735.

2. García Del Blanco N, Dobson ME, Vela AI, et al. Genotyping of Francisella tularensis Strains by Pulsed-Field Gel Electrophoresis, Amplified Fragment Length Polymorphism Fingerprinting, and 16S rRNA Gene Sequencing. J Clin Microbiol. 2002;40(8):2964-2972.

3. Arata A, Chamsa H, Farhang-Azad A, et al. First detection of tularaemia in domestic and wild mammals in Iran. Bull World Health Organ. 1973;49(6):597-603.

4. Plague Manual: Epidemiology, Distribution, Surveillance and Control. World Health Organization Communicable Disease Surveillance and Response; 1999.

5. Karimi P. Discovery of a new focus of zoonotic plague in the eastern Azarbaidjan region of Iran. Bull Soc Pathol Exot Filiales. 1980;73(1):2835 .

6. Nekoui H, Razavi MR. Seiedipour GH. Investigation of yersinia pestis in Xenopsylla astia. Southeast Asian J Trop Med Public Health. 2003;34 Suppl 2:158-161.

7. Nekouie H, Asmar M, Razavi MR. Determination of Sensitivity of Different Endemic Strain of Yersinia Pestis To Antibiotics Available In Iran. Medicine and Purification. 1998;30:9-12.

8. Nekouie H, Asmar M. Yersinia pestis Diagnosis by IFA in Fleas. The first congress on clinical diagnosis. Iran: University of Uromieh; 1992.

9. Karami A. Serological cross reaction of Yersinia pestis and yersinia ebtrocolotica and immunity against yersinia pestis. Msc thesis; 1993.

10. World Health Organization. International meeting on preventing and controlling plague: the old calamity still has a future. Wkly Epidemiol Rec. 2006;81(28):278-284. 